Original research article

\title{
Association of FGF19, FGF21 and FGF23 with carbohydrate metabolism parameters and insulin resistance in patients with chronic kidney disease
}

\author{
Małgorzata Marchelek-Myśliwiec ${ }^{1}$, Violetta Dziedziejko ${ }^{2}$, Katarzyna Dołęgowka ${ }^{1}$, \\ Andrzej Pawlik ${ }^{3}{ }^{*}$, Krzysztof Safranow ${ }^{2}$, Joanna Stępniewska ${ }^{1}$, Magda Wiśniewska ${ }^{1}$, \\ Jolanta Małyszko ${ }^{4}$, Kazimierz Ciechanowski ${ }^{1}$ \\ ${ }^{1}$ Pomeranian Medical University, Clinical Department of Nephrology, Transplantology and Internal Medicine, Szczecin, Poland \\ ${ }^{2}$ Pomeranian Medical University, Department of Biochemistry and Medical Chemistry, Szczecin, Poland \\ ${ }^{3}$ Pomeranian Medical University, Department of Physiology, Szczecin, Poland \\ ${ }^{4}$ Warsaw Medical University, Department of Nephrology, Dialysis and Internal Medicine, Warsaw, Poland
}

\begin{abstract}
Insulin resistance (IR) is characterised by increased gluconeogenesis in the liver and the resistance of peripheral receptors to insulin. Several factors, including IR, type 2 diabetes, new-onset diabetes after transplant (NODAT) and secondary parathyroidism, are related to chronic kidney disease (CKD). These factors are associated with higher mortality due to the increased risk of cardiovascular complications. Many factors have been identified as potential markers of IR in CKD. These factors include fibroblast growth factors (FGFs), a subfamily of endocrine polypeptides. In this study, we examined the association of FGF19, FGF21 and FGF23 with selected parameters related to carbohydrate metabolism and insulin resistance in non diabetic patients with predialysis CKD and in non diabetic patients after renal transplantation.

The study included 108 non diabetic subjects: 40 patients with predialysis CKD, 45 patients with CKD who had undergone renal transplantation, and 23 healthy subjects (control group).

In patients who had undergone renal transplantation, concentrations of FGF23 were increased compared to the control group and patients with predialysis CKD. The highest and lowest FGF19 concentrations were observed in CKD patients and in patients who had undergone kidney transplantation, respectively. This difference was statistically significant. Leptin concentrations were higher in CKD patients compared to the control group and patients who had undergone kidney transplantation. There were no statistically significant differences in adiponectin concentrations, lean body mass or fat tissue mass between the studied groups. HOMA-IR and insulin levels were significantly increased in CKD patients and in patients who had undergone renal transplantation in comparison to the control group.

The results of the study suggest the involvement of FGF in carbohydrate metabolism and insulin resistance in patients with predialysis $\mathrm{CKD}$, as well as a correlation with kidney function.
\end{abstract}

Keywords: Body composition; Chronic kidney disease; FGF19; FGF21; FGF23; Insulin

Highlights:

- Insulin resistance is characterised by increased gluconeogenesis.

- Chronic kidney disease (CKD) is associated with insulin resistance.

- Fibroblast growth factors are involved in carbohydrate metabolism and insulin resistance in patients with predialysis CKD.

Abbreviations: FGF, fibroblast growth factor; CKD, chronic kidney disease; HDL, high-density lipoprotein;

LDL, low-density lipoprotein

\section{Introduction}

Insulin is a hormone produced by pancreatic beta cells that plays an important role in carbohydrate, lipid and protein metabolism. Insulin resistance (IR) is characterised by the impaired action of insulin on tissues and organs, and is associat- ed with several diseases. IR may be associated with increased gluconeogenesis in the liver and resistance of peripheral receptors to insulin. As a result, the pancreas produces more insulin, leading to hyperinsulinemia. This phenomenon also occurs in chronic kidney disease (CKD), arising in the early stages of the disease (Fliser et al., 1998; Spoto et al., 2016). IR has a significant impact on the progression of kidney disease, especially

\footnotetext{
* Author for correspondence: Andrzej Pawlik, Pomeranian Medical University, Department of Physiology, Powstancow Wlkp 72 70-111 Szczecin, Poland; e-mail: pawand@poczta.onet.pl http://doi.org/10.32725/jab.2020.005

Submitted: 2019-04-01 • Accepted: 2020-02-11 • Prepublished online: 2020-02-28

J Appl Biomed 18/2-3: 61-69 • EISSN 1214-0287 • ISSN 1214-021X

(c) 2020 The Authors. Published by University of South Bohemia in České Budějovice, Faculty of Health and Social Sciences.

This is an open access article under the CC BY-NC-ND license.
} 
cardiovascular complications (CV) (Kurşat et al., 2010). IR can persist even after successful kidney transplantation, and can progress to new-onset diabetes after transplant (NODAT) with the initiation of immunosuppressive therapy. Because IR is a modifiable risk factor, its reduction may lower cardiovascular mortality in patients with $C K D$. The mechanism of IR in CKD is mainly related to peripheral resistance, and is associated with endothelial dysfunction (Voytovich et al., 2006). Many newly discovered markers are potentially related to IR in CKD. Recent research highlighted the use of cytokines and adipocytokines that are known to influence insulin sensitivity as potential biomarkers of IR. These factors include the subfamily of endocrine polypeptides known as fibroblast growth factors (FGF) (Garland et al., 2014; Hui et al., 2018; Kliewer and Mangelsdorf, 2015; Sit et al., 2018; Strowski, 2017; Tanajak et al., 2018). These proteins ameliorate IR through various mechanisms that act to stimulate glucose uptake, and are considered therapeutic targets in diseases characterised by IR including obesity, CKD and diabetes (Fernandes-Freitas and Owen, 2015).

In 1999, FGF19 was first discovered in the human brain, and was subsequently detected in many other tissues. The basic roles of FGF19 are related to bile acid secretion, stimulation of glycogen synthesis and inhibition of gluconeogenesis by inhibiting the expression of the transcription factor peroxisome proliferator-activated receptor-gamma coactivator alpha (PGCa) and its target genes (Fukumoto, 2008; Zhang et al., 2015). Previous studies have reported elevated levels of FGF19 in CKD; however, its role in CKD is not fully understood. In addition, Reiche et al. (2010) observed that the serum FGF19 concentration was 1.5 times higher in haemodialysis patients compared to healthy subjects.

FGF21 is primarily found in the liver and adipose tissue, as well as in the skeletal muscle, heart, kidneys and testes (Fukumoto, 2008; Zhang et al., 2015). FGF21 plays important roles in ketogenesis, gluconeogenesis, weight loss, thermogenesis and transformation of white to brown adipose tissue (Nishimura et al., 2000). FGF21 increases glucose tolerance and insulin sensitivity, and also reduces blood glucose levels. Importantly, an overdose of FGF21 does not lead to hypoglycaemia as with insulin. Recent studies suggest that the FGF21 agonist is a promising therapeutic agent for the treatment type 2 diabetes and obesity (Hu et al., 2018). Furthermore, FGF21 was found to be closely associated with renal dysfunction in subjects with end-stage renal disease (ESRD) (Han et al., 2010). There is also an association between serum FGF21 levels and the rate of cardiovascular events and mortality in hemodialysis patients (Suassuna et al., 2019).

FGF23 is a phosphatonine that is produced in response to phosphate retention in $C K D$, and therefore plays a role in regulating phosphate serum concentrations. Previous studies have confirmed the association of FGF23 with the progression of kidney disease, inflammation, vascular calcification and left ventricular hypertrophy (Isakova et al., 2018; Liu and Quarles, 2007). The involvement of FGF23 in carbohydrate metabolism and IR in patients with CKD is not known.

Both IR and type 2 diabetes are important factors in the progression of CKD to ESRD, and are associated with increased mortality due to cardiovascular complications.

In our previous studies we have indicated that increased concentrations of FGF19 and FGF21 in patients with CKD may be associated with the metabolism of lipids and carbohydrates (Marchelek-Myśliwiec et al., 2019a). Additionally haemodialysis and transplantation resulted in the reduction of FGF19 and FGF21 concentrations in patients with CKD (Marche-
lek-Myśliwiec et al., 2019b). Therefore, in this study we examined the association of FGF19, FGF21 and FGF23 with selected parameters of carbohydrate metabolism and insulin resistance in non diabetic patients with predialysis CKD and in non diabetic patients after renal transplantation.

\section{Materials and methods}

\section{Study groups}

The study included 108 non diabetic subjects: 40 patients with predialysis CKD, 45 patients with CKD who had undergone renal transplantation, and 23 healthy subjects as the control group. The inclusion criteria for the control group (C) were as follows: aged over 18 years, no chronic inflammatory diseases (e.g., systemic lupus erythematosus, rheumatoid arthritis), no diabetes, and a glomerular filtration rate (GFR) above $60 \mathrm{ml} / \mathrm{min} / 1.73 \mathrm{~m}^{2}$. The following inclusion criteria were applied to the predialysis CKD group: aged over 18 years, no diabetes, no need for haemodialysis or renal replacement therapy, and stable renal function for 3 months prior to enrolment. The exclusion criteria for this group were cancer and/or treatment with steroids at a dose of more than $5 \mathrm{mg}$ /day.

The causes of kidney insufficiency were as follows: hypertension, autosomal dominant polycystic kidney disease, glomerulonephritis, congenital urinary tract malformations and nephrolithiasis. The inclusion criteria for transplant patients (Tx) were the following: renal transplantation at least 2 years before enrolment, no diabetes, constant doses of immunosuppressive drugs for the last 3 months, and standard immunosuppression with calcineurin inhibitors, mycophenolate mofetil and glucocorticosteroids. The exclusion criteria were neoplastic disease and/or bariatric surgery. This study was approved by the Bioethical Commission at the Pomeranian Medical University. All participants provided written informed consent.

\section{Materials}

Blood samples for the C, CKD and Tx groups were collected from the peripheral vein (using Sarstedt S-Monovette tubes with clotting activator) after an overnight fast. Whole blood was centrifuged, and the serum samples were frozen at $-80^{\circ} \mathrm{C}$ until use.

\section{Determination of biochemical parameters}

Lipid profile (total cholesterol, HDL and LDL cholesterol, triacylglycerols), glucose, creatinine, uric acid, urea, albumin, total protein, sodium, potassium, magnesium concentrations were determined in serum using the Architect c8000 analyser (ABBOTT, USA). The GFR was estimated using the CKD-EPI equation (eGFR). The insulin concentration was determined by an immunoenzymatic method (ELISA; uIU/ml; R\&D). HOMA-IR was calculated according to the formula (glucose $(\mathrm{mg} / \mathrm{dl}) \times$ insulin $(\mathrm{uIU} / \mathrm{ml})) / 405(\mathrm{mg} / \mathrm{dl} \times \mu \mathrm{IU} / \mathrm{ml})$. The serum concentrations of leptin $(\mathrm{ng} / \mathrm{ml})$ and adiponectin $(\mu \mathrm{g} / \mathrm{ml})$ in the samples were determined by ELISA (Bio Vendor, Czech Republic), and the concentrations of FGF19, FGF21 and FGF23 (pg/ml) were determined by ELISA (Cusabio Biotech, Wuhan, China).

\section{Determination of body composition}

Measurements of adipose tissue content (BF) and lean body mass (LM) were made using the dual X-ray absorptiometer (DXA) method (Lunar Prodigy Advance, GE Healthcare), and the results are expressed in kilograms. 


\section{Statistical analysis}

Non-parametric tests were used for statistical analysis of quantitative variables (Shapiro-Wilk test). The Mann-Whitney $U$ test was used for comparisons between two groups, and Spearman's rank correlation coefficient for the assessment of associations between variables within groups. Values of $p<0.05$ were considered to indicate statistical significance for all analyses.

\section{Results}

\section{General characteristics and laboratory data}

The baseline characteristics of the study groups are shown in Table 1.

Table 1. The baseline characteristics of the study groups

\begin{tabular}{|c|c|c|c|c|c|c|}
\hline \multirow[t]{2}{*}{ Parameters } & $\begin{array}{c}C \\
n=23\end{array}$ & $\begin{array}{c}\text { Predialysis } \\
\text { CKD } \\
n=40\end{array}$ & $\begin{array}{c}\text { Tx } \\
n=45\end{array}$ & $C$ vs $C K D$ & C vs Tx & CKD vs Tx \\
\hline & \multicolumn{3}{|c|}{ Mean \pm SD } & \multicolumn{3}{|c|}{$p^{\mathrm{A}}$} \\
\hline Age (years) & $53.8 \pm 13.2$ & $59.9 \pm 8.9$ & $54.2 \pm 12.4$ & 0.073 & 0.99 & 0.030 \\
\hline Body weight $(\mathrm{kg})$ & $76.4 \pm 15.1$ & $80.7 \pm 15.3$ & $75.5 \pm 14.3$ & 0.25 & 0.84 & 0.11 \\
\hline BMI $\left(\mathrm{kg} / \mathrm{m}^{2}\right)$ & $26.6 \pm 4.1$ & $28.8 \pm 5.0$ & $26.4 \pm 3.6$ & 0.29 & 0.62 & 0.052 \\
\hline $\operatorname{GFR}\left(\mathrm{ml} / \mathrm{min} / 1.73 \mathrm{~m}^{2}\right)$ & $91.1 \pm 17.1$ & $36.2 \pm 13.7$ & $57.9 \pm 22.3$ & $<0.000001$ & $<0.000001$ & 0.0000043 \\
\hline Creatinine (mg/dl) & $0.8 \pm 0.1$ & $2.0 \pm 0.8$ & $1.5 \pm 0.6$ & $<0.000001$ & $<0.000001$ & 0.0012 \\
\hline Uric acid (mg/dl) & $4.5 \pm 1.3$ & $5.3 \pm 1.1$ & $5.5 \pm 1.7$ & 0.027 & 0.016 & 0.92 \\
\hline Urea (mg/dl) & $33.3 \pm 7.8$ & $73.0 \pm 27.1$ & $53.7 \pm 23.6$ & $<0.000001$ & 0.000078 & 0.00061 \\
\hline Albumin (g/dl) & $3.6 \pm 0.7$ & $4.0 \pm 0.9$ & $3.2 \pm 0.4$ & 0.16 & 0.016 & 0.00035 \\
\hline Total protein $(\mathrm{g} / \mathrm{dl})$ & $6.4 \pm 1.3$ & $7.2 \pm 1.5$ & $6.0 \pm 0.9$ & 0.018 & 0.25 & 0.000019 \\
\hline Sodium $(\mathrm{mmol} / \mathrm{l})$ & $140.0 \pm 1.7$ & $140.3 \pm 2.2$ & $139.3 \pm 2.9$ & 0.51 & 0.28 & 0.061 \\
\hline Potassium (mmol/l) & $4.4 \pm 0.3$ & $4.5 \pm 0.5$ & $4.4 \pm 0.5$ & 0.12 & 0.70 & 0.049 \\
\hline Magnesium (mmol/l) & $0.91 \pm 0.10$ & $0.87 \pm 0.13$ & $0.86 \pm 0.10$ & 0.054 & 0.12 & 0.85 \\
\hline Glucose (mg/dl) & $97.2 \pm 21.2$ & $100.4 \pm 22.4$ & $96.2 \pm 12.7$ & 0.16 & 0.26 & 0.57 \\
\hline $\mathrm{CH}(\mathrm{mg} / \mathrm{dl})$ & $182.7 \pm 23.7$ & $188.7 \pm 36.0$ & $193.6 \pm 36.3$ & 0.76 & 0.22 & 0.34 \\
\hline $\mathrm{LDL}(\mathrm{mg} / \mathrm{dl})$ & $109.8 \pm 23.5$ & $117.9 \pm 36.0$ & $115.9 \pm 31.5$ & 0.43 & 0.55 & 0.99 \\
\hline $\mathrm{HDL}(\mathrm{mg} / \mathrm{dl})$ & $39.2 \pm 8.2$ & $36.0 \pm 8.5$ & $42.1 \pm 14.5$ & 0.17 & 0.90 & 0.20 \\
\hline $\mathrm{TG}(\mathrm{mg} / \mathrm{dl})$ & $163.9 \pm 35.7$ & $183.9 \pm 52.1$ & $176.4 \pm 44.2$ & 0.18 & 0.28 & 0.75 \\
\hline $\begin{array}{l}\text { A Mann-Whitney } U \text { test } \\
\text { C, control group; CKD, } \\
\text { BMI, body mass index; } \\
\text { Statistically significant }\end{array}$ & $\begin{array}{l}\text { patients with } \\
\text { ular filtration } \\
.05 \text { ) are mark }\end{array}$ & $\begin{array}{l}\text { lysis chronic } \\
\mathrm{CH} \text {, total cho } \\
\text { pold. }\end{array}$ & $\begin{array}{l}\text { y disease; Tx } \\
\text { l; LDL, LDL }\end{array}$ & $\begin{array}{l}\text { betic patie } \\
\text { rol; HDL, }\end{array}$ & $\begin{array}{l}\text { enal trans } \\
\text { terol; TG, }\end{array}$ & $\begin{array}{l}\text { on; } \\
\text { lycerols. }\end{array}$ \\
\hline
\end{tabular}

The highest FGF19 concentrations were observed in predialysis CKD patients and the lowest in patients who had undergone kidney transplantation (Fig. 1A). The differences were statistically significant. The highest FGF21 concentrations were in predialysis CKD patients; however, the differences were not statistically significant (Fig. 1B). In patients who had undergone renal transplantation, we observed increased concentrations of FGF23 compared to the control group and patients with predialysis CKD (Fig. 1C).

The insulin levels and HOMA-IR values were significantly increased in predialysis CKD patients and in patients who had undergone renal transplantation in comparison to the control group (Fig. 2A, B). Leptin concentrations were increased in predialysis CKD patients compared to the control group and patients after kidney transplantation (Fig. 2C). There were no statistically significant differences in adiponectin concentrations (Fig. 2D), lean body mass or fat tissue between the studied groups (Fig. $3 \mathrm{~A}, \mathrm{~B}$ ).

\section{Correlations}

In predialysis CKD patients and patients who had undergone renal transplantation, FGF19 was negatively correlated with GFR $\left(\mathrm{R}_{\mathrm{S}}=-0.74 p<0.0001\right.$ and $\left.\mathrm{R}_{\mathrm{S}}=-0.65 p<0.0001\right)$. Moreover, in predialysis CKD patients, FGF21 was negatively correlated with leptin levels (Fig. 4A), positively correlated with lean body mass $\left(R_{S}=0.34 p=0.030\right)$ and there was no statistically significant correlations with adiponectin level (Fig. 4B). In CKD and Tx groups FGF21 concentrations were positively correlated with HOMA-IR and insulin levels (Fig. 4C, D and Fig. 5C, D). In patients who had undergone renal transplantation, FGF21 was negatively correlated with leptin levels (Fig. 5A) and GFR $\left(R_{S}=-0.54 p=0.00015\right)$ and positively correlated with adiponectin (Fig. 5B). There were no statistically significant correlations between FGF23 concentration and any of the studied parameters (BMI, GFR, leptin, adiponectin, BF, LM, glucose, insulin, HOMA-IR) in studied groups. 

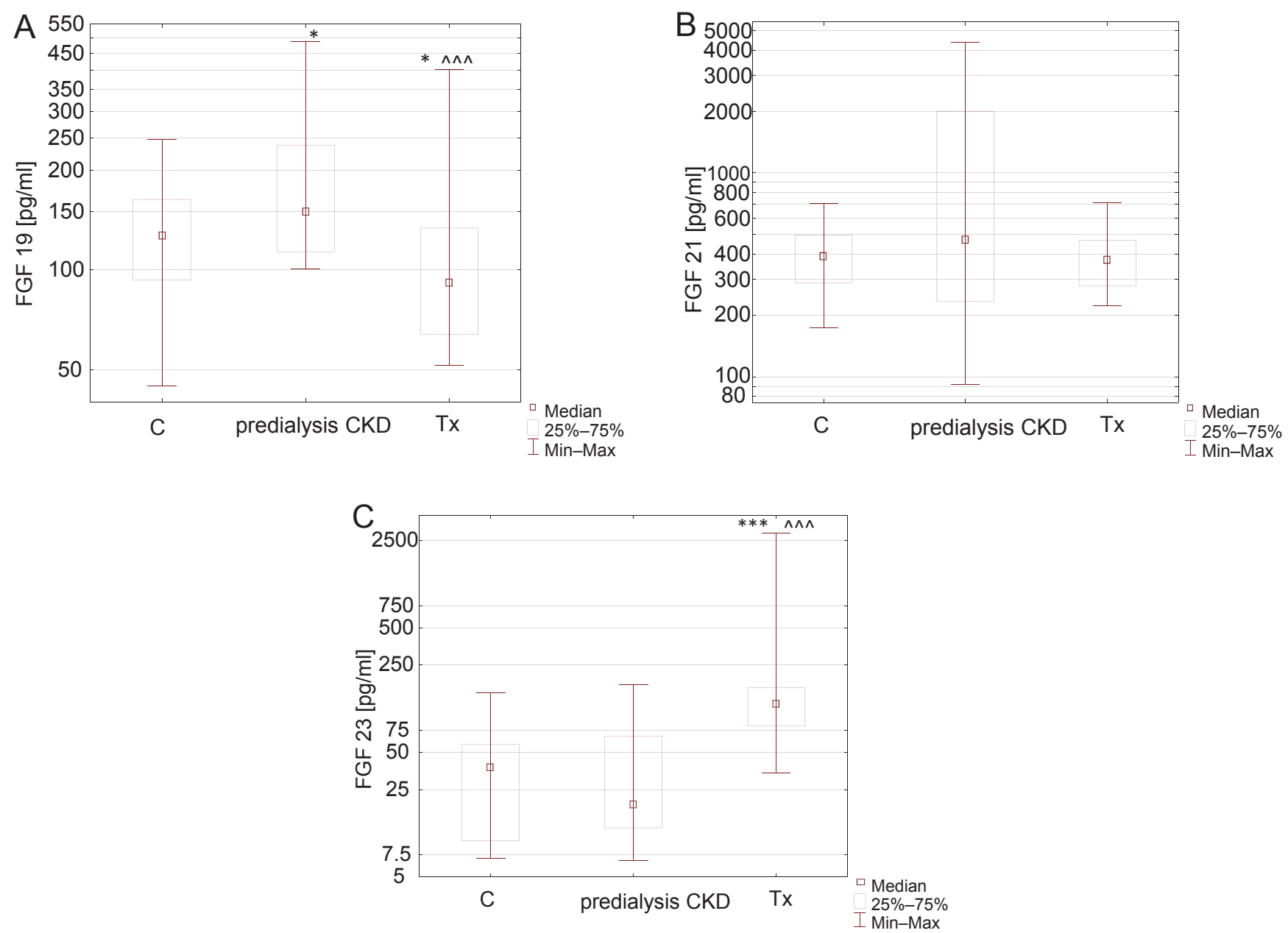

Fig. 1. Concentrations of fibroblast growth factors 19, 21 and 23 in patients with chronic kidney disease, patients after renal transplantation and controls

Concentrations of FGF19, FGF21, FGF23 are shown on logarithmic scale.

${ }^{*} p<0.05,{ }^{* *} p<0.01,{ }^{* * *} p<0.001$ vs control group

$\wedge p<0.05, \wedge \wedge p<0.01,{ }^{\wedge \wedge \wedge} p<0.001$ vs CKD group

$C$, control group; $C K D$, non diabetic patients with predialysis chronic kidney disease; $\mathrm{Tx}$, non diabetic patients after renal transplantation. 

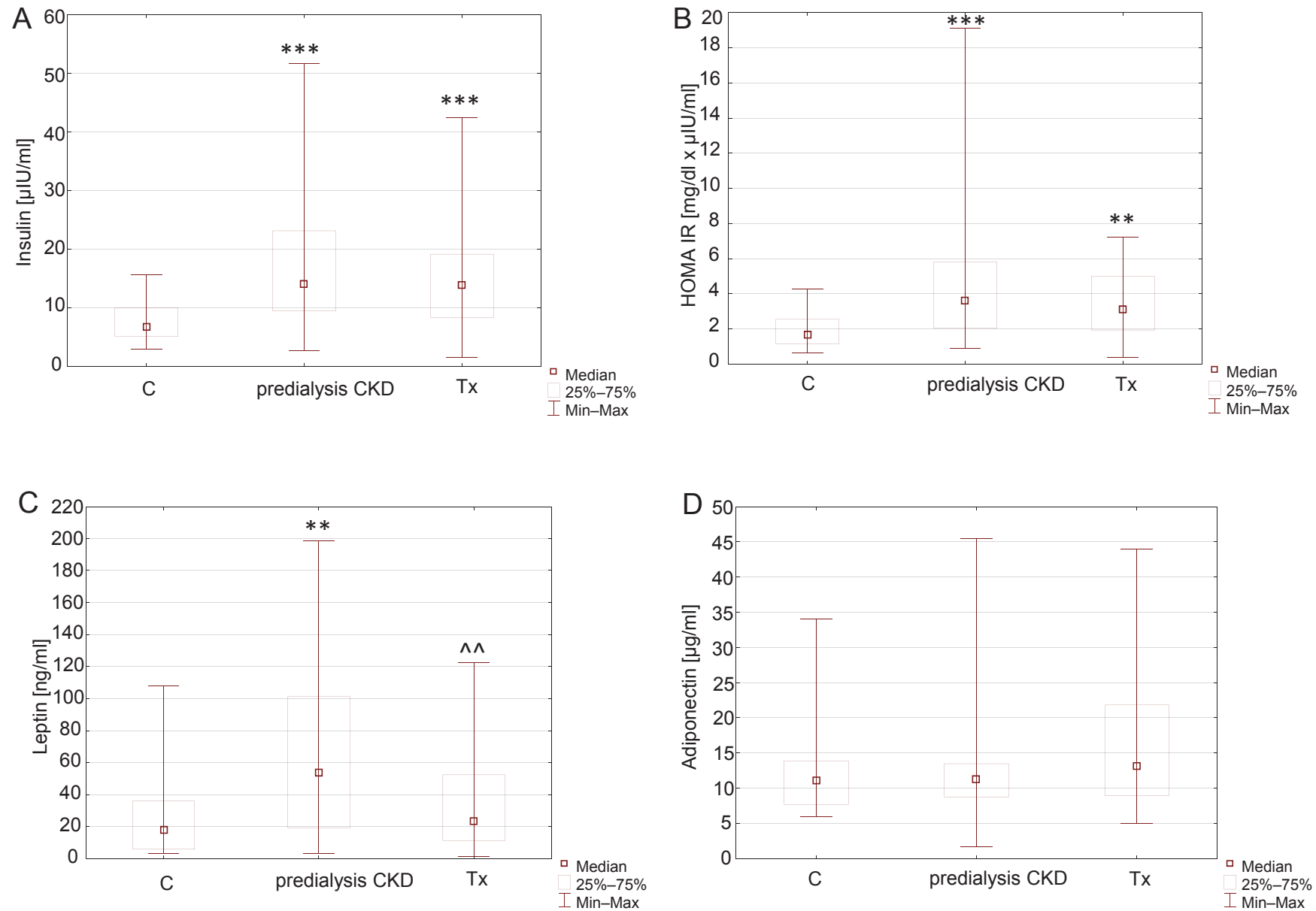

Fig. 2. Selected parameters of carbohydrate metabolism in patients with chronic kidney disease, patients after renal transplantation and controls
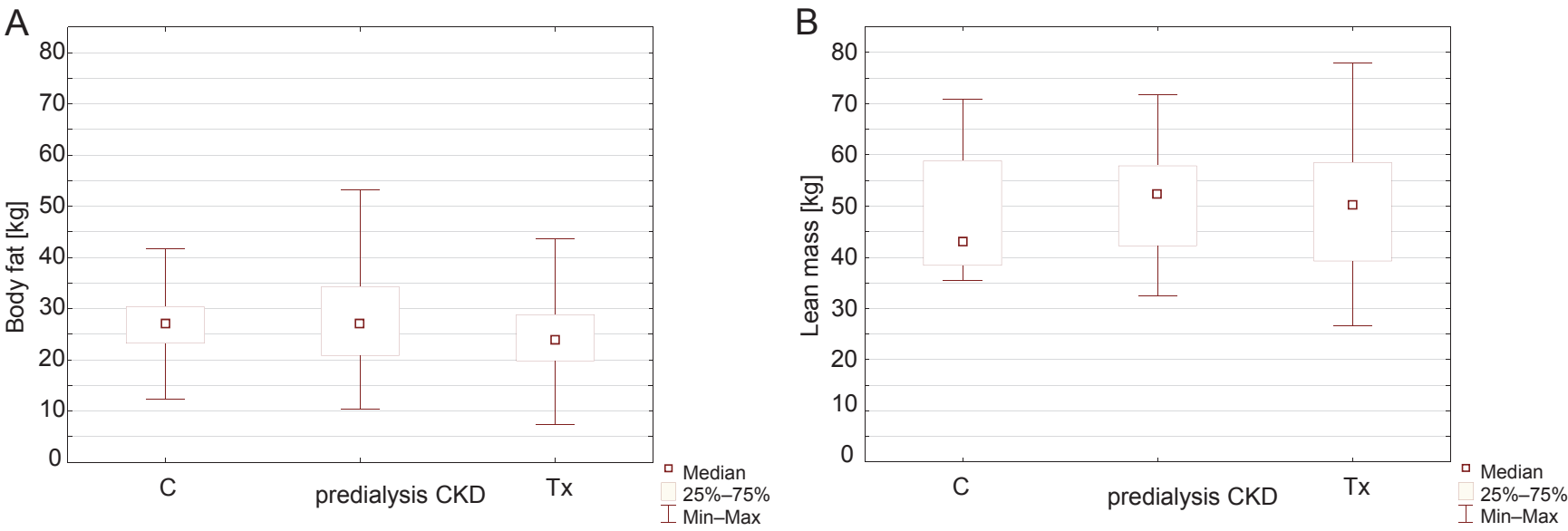

Fig. 3. Content of body fat and lean mass in patients with chronic kidney disease, patients after renal transplantation and controls 


\section{Predialysis CKD}
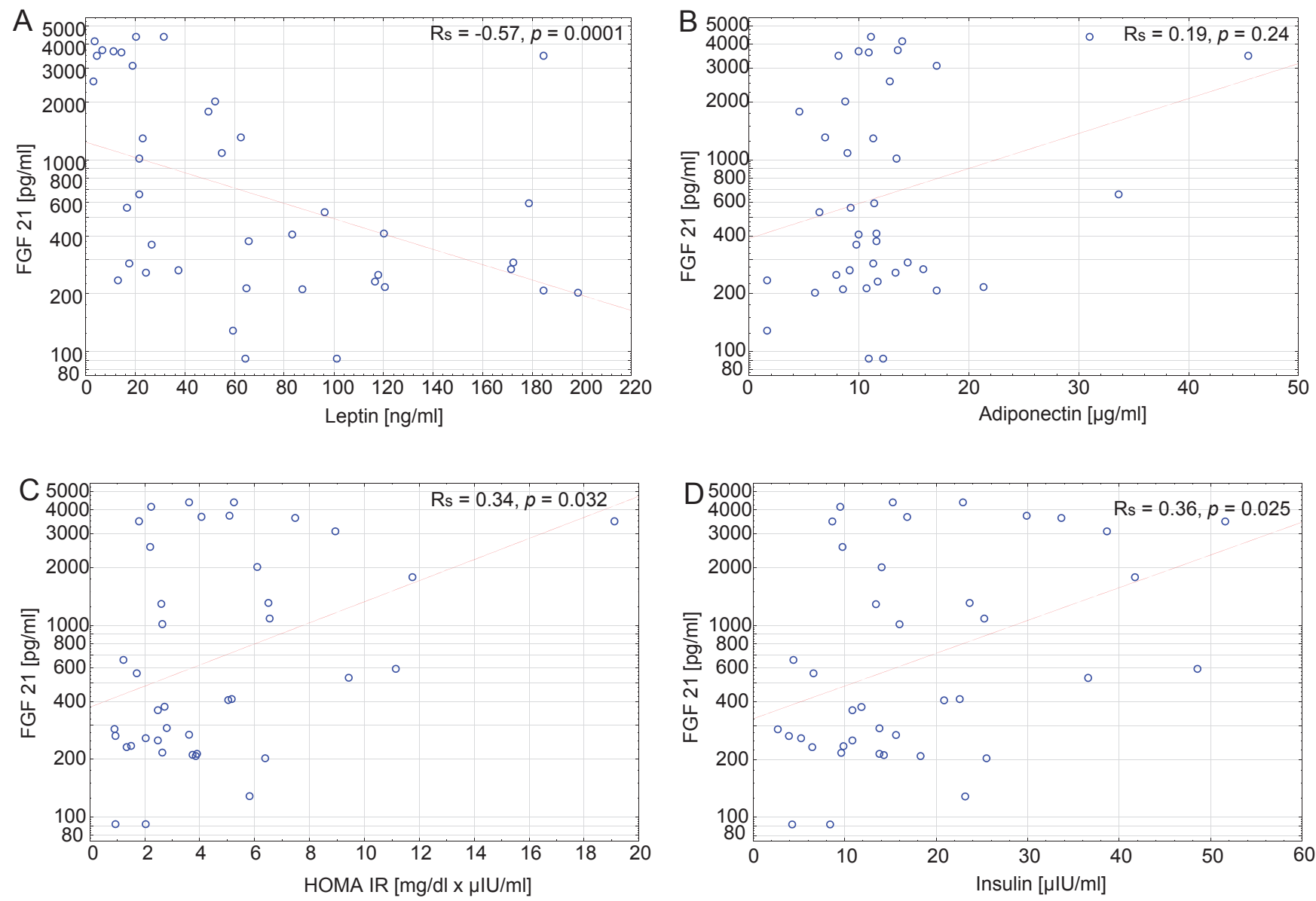

Fig. 4. Correlations between fibroblast growth factor 21 and selected parameters of carbohydrate metabolism in patients with chronic kidney disease

Concentrations of FGF21 are shown on logarithmic scale. Spearman rank correlation coefficient is presented with corresponding $p$-value.

\section{Discussion}

In this study, we examined the association between FGF and selected parameters of carbohydrate metabolism and insulin resistance (IR) in patients with predialysis CKD. IR commonly accompanies CKD and worsens its prognosis. In recent years, several new factors have been found to be significantly associated with IR (Degirolamo et al., 2016; Kharitonenkov and Shanafelt, 2009; Liu and Quarles, 2007). In our study, we analysed the FGF subfamily and its relationship to carbohydrate metabolism, IR and body mass composition in a group of patients with predialysis CKD. The FGF19 concentrations were negatively correlated with GFR in the CKD and Tx groups. This confirms the association of FGF19 with renal function.

We did not observe an association between FGF19 concentrations and parameters of carbohydrate or lipid metabolism or HOMA-IR. Animal studies have shown that exogenous administration of FGF19 can reduce body weight and alter fat tissue distribution (Tomlinson et al., 2002). In a study by $\mathrm{Hu}$ et al. (2018), FGF19 concentrations were found to depend on the amount of adipose tissue accumulated, and were independent of carbohydrate disorders. In our study, we did not find any correlations between FGF19 and the amounts of adipose tissue or lean body mass.

Previous studies have reported increased FGF21 levels in patients with diabetes, obesity, arteriosclerosis and CKD (Mraz et al., 2009). In our study, FGF21 was negatively correlated with GFR in the Tx group, but this correlation was absent in the predialysis CKD and control groups. Interestingly, the concentrations of FGF21 observed in the CKD group were three times higher than in the control and Tx groups, but this difference did not reach statistical significance.

Attempts to explain the elevated concentrations of FGF21 in CKD are based on three concepts. The first one is a compensatory FGF21 response to metabolic stress, while the second concerns the resistance of target tissues to FGF21. The third hypothesis considers the impaired excretion of FGF21 by the kidneys at low GFR (Anuwatmatee et al., 2019; Stein et al., 2009). In contrast to FGF19, we observed a positive correlation of FGF21 with the HOMA-IR index and insulin concentration in all groups. 
Tx
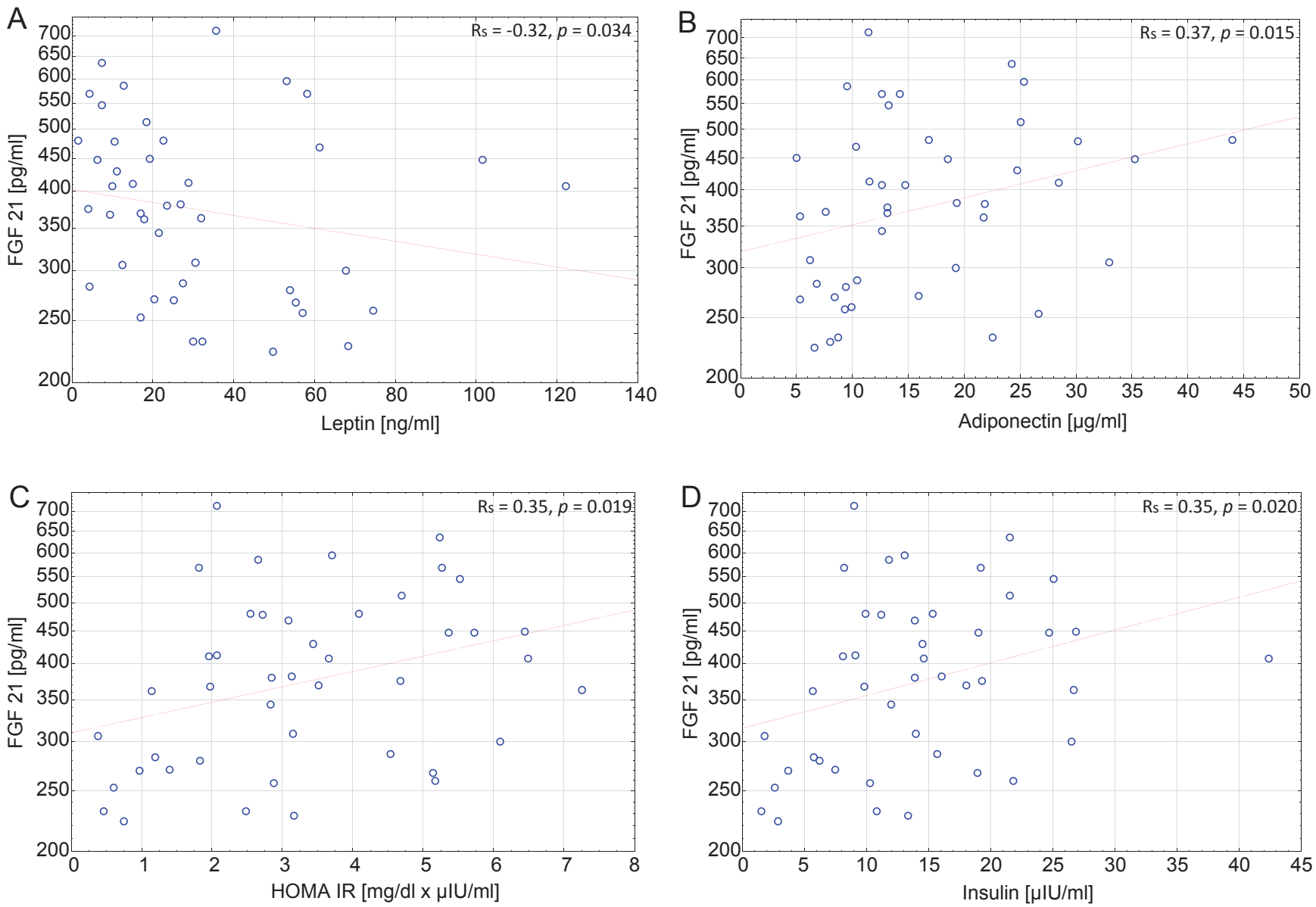

Fig. 5. Correlations between fibroblast growth factor 21 and selected parameters of carbohydrate metabolism in patients after renal transplantation

Concentrations of FGF21 are shown on logarithmic scale. Spearman rank correlation coefficient is presented with corresponding $p$-value.

FGF21 is a late-acting hypoglycaemic hormone. In an animal model, it was demonstrated that the main mechanism of action of FGF21 in terms of glycaemic control is to increase the sensitivity of target tissues to insulin (Coskun et al., 2008). In humans, a study using an FGF21 analogue showed beneficial effects on the lipid profile, adiponectin concentrations and weight loss (Gaich et al., 2013). Our results suggest that FGF21, regardless of renal function, may be a marker of IR. Lin et al. (2010) showed a positive correlation between FGF21 and the amount of subcutaneous fat in obese people with normal insulin sensitivity. Other studies have confirmed an association of FGF21 with adipose tissue and the production of adiponectin (Zhang et al., 2015). Treatment with FGF21 enhanced both expression and secretion of adiponectin in adipocytes, thereby increasing serum levels of adiponectin (Lin et al., 2013). In our study, FGF21 was positively correlated with the adiponectin concentration in the Tx group and negatively correlated with the leptin concentration in the predialysis CKD and Tx groups. In a study by Asrih et al. (2016) conducted in vivo in an animal model and in vitro on human-derived hepatocarcinoma cells, elevated FGF21 concentrations were observed after leptin administration.
In our study, FGF23 was not correlated with parameters of carbohydrate metabolism and body composition. In a previous study by Fayed et al. (2018), FGF23 was found to be an important predictor of IR in CKD patients. In contrast, Hanks et al. (2015) found that FGF23 was not correlated with IR in a group of patients with CKD. Zaheer et al. (2017) showed that BMI and adipose tissue mass were positively correlated with FGF23 in patients with CKD. In another study performed in subjects with simple obesity, a negative correlation was found between FGF23 and HOMA-IR and insulin concentration (Wojcik et al., 2012).

FGF19, FGF21 and FGF23 are involved in the transmission of a number of signals that maintain homeostasis of the body. FGF concentrations are known to be altered in many common and chronic diseases such as obesity, diabetes and CKD, therefore, FGFs can be considered biomarkers of these diseases. Currently, research is being carried out on the use of FGFs as a therapy in liver diseases, type 2 diabetes and obesity, as well as to treat complications of kidney disease. Further studies are needed in CKD patients to explain the role of the FGF19 subfamily in kidney disease. 


\section{Conclusions}

The results of this study suggest the involvement of FGFs in carbohydrate metabolism and insulin resistance in patients with predialysis CKD, as well as a correlation with kidney function. FGF19 was found to be negatively correlated with GFR. FGF21 concentrations were positively correlated with insulin levels, HOMA-IR and lean body mass.

\section{Acknowledgements}

This work was supported by the National Centre of Science in Poland under grant number N402 564040.

\section{Conflict of interests}

The authors declare that they have no conflicts of interests.

\section{References}

Anuwatmatee S, Tang S, Wu BJ, Rye KA, Ong KL (2019). Fibroblast growth factor 21 in chronic kidney disease. Clin Chim Acta 489: 196-202. DOI: 10.1016/j.cca.2017.11.002.

Asrih M, Veyrat-Durebex C, Poher AL, Lyautey J, RohnerJeanrenaud F, Jornayvaz FR (2016). Leptin as a Potential Regulator of FGF21. Cell Physiol Biochem 38(3): 1218-1225. DOI: $10.1159 / 000443070$

Coskun T, Bina HA, Schneider MA, Dunbar JD, Hu CC, Chen Y, et al. (2008). Fibroblast growth factor 21 corrects obesity in mice. Endocrinology 149(12): 6018-6027. DOI: 10.1210/en.2008-0816.

Degirolamo C, Sabbà C, Moschetta A (2016). Therapeutic potential of the endocrine fibroblast growth factors FGF19, FGF21 and FGF23. Nat Rev Drug Discov 15(1): 51-69. DOI: 10.1038/nrd.2015.9.

Fayed A, El Nokeety MM, Heikal AA, Abdulazim DO, Naguib MM, El Din UAAS (2018). Fibroblast growth factor-23 is a strong predictor of insulin resistance among chronic kidney disease patients. Ren Fail 40(1): 226-230. DOI: 10.1080/0886022X.2018.1455594.

Fernandes-Freitas I, Owen BM (2015). Metabolic roles of endocrine fibroblast growth factors. Curr Opin Pharmacol 25: 30-35. DOI: 10.1016/j.coph.2015.09.014.

Fliser D, Pacini G, Engelleiter R, Kautzky-Willer A, Prager R, Franek E, et al. (1998). Insulin resistance and hyperinsulinemia are already present in patients with incipient renal disease. Kidney Int 53(5): 1343-1347. DOI: 10.1046/j.1523-1755.1998.00898.x.

Fukumoto $S$ (2008). Actions and mode of actions of FGF19 subfamily members. Endocr J 55(1): 23-31. DOI: 10.1507/ endocrj.kr07e-002.

Gaich G, Chien JY, Fu H, Glass LC, Deeg MA, Holland WL, et al (2013). The effects of LY2405319, an FGF21 analog, in obese human subjects with type 2 diabetes. Cell Metab 18(3): 333-340. DOI: 10.1016/j.cmet.2013.08.005.

Garland JS, Holden RM, Ross R, Adams MA, Nolan RL, Hopman WM, et al. (2014). Insulin resistance is associated with Fibroblast Growth Factor-23 in stage 3-5 chronic kidney disease patients. J Diabetes Complications 28(1) 61-65. DOI: 10.1016/j. jdiacomp.2013.09.004.

Han SH, Choi SH, Cho BJ, Lee Y, Lim S, Park YJ, et al. (2010). Serum fibroblast growth factor-21 concentration is associated with residual renal function and insulin resistance in endstage renal disease patients receiving long-term peritoneal dialysis. Metabolism 59(11): 1656-1662. DOI: 10.1016/j. metabol.2010.03.018. DOI: 10.1371/journal.pone.0122885.

Hanks LJ, Casazza K, Judd SE, Jenny NS, Gutiérrez OM (2015). Associations of fibroblast growth factor-23 with markers of inflammation, insulin resistance and obesity in adults. PLoS One 10(3): e0122885. DOI: 10.1371/journal.pone.0122885.

Hu X, Xiong Q, Xu Y, Zhang X, Pan X, Ma X, et al. (2018). Association of serum fibroblast growth factor 19 levels with visceral fat accumulation is independent of glucose tolerance status. Nutr Metab Cardiovasc Dis 28(2): 119-125. DOI: 10.1016/j. numecd.2017.10.009.

Hui Q, Jin Z, Li X, Liu C, Wang X (2018). FGF Family: From Drug Development to Clinical Application. Int J Mol Sci 19(7) pii: E1875. DOI: 10.3390/ijms19071875.

Isakova T, Cai X, Lee J, Xie D, Wang X, Mehta R, et al. (2018). Longitudinal FGF23 Trajectories and Mortality in Patients with CKD. J Am Soc Nephrol 29(2): 579-590. DOI: 10.1681/ ASN.2017070772.

Kharitonenkov A, Shanafelt AB (2009). FGF21: a novel prospect for the treatment of metabolic diseases. Curr Opin Investig Drugs 10(4): 359-364. PMID: 19337957.

Kliewer SA, Mangelsdorf DJ (2015). Bile Acids as Hormones: The FXR-FGF15/19 Pathway. Dig Dis 33(3): 327-331. DOI: $10.1159 / 000371670$.

Kurşat S, Colak HB, Toraman A, Tekçe H, Ulman C, Bayturan O (2010). Relationship of insulin resistance in chronic haemodialysis patients with inflammatory indicators, malnutrition, echocardiographic parameters and 24 hour ambulatory blood pressure monitoring. Scand J Urol Nephrol 44(4): 257-264. DOI: 10.3109/00365591003733682.

Lin Z, Tian H, Lam KS, Lin S, Hoo RC, Konishi M, et al. (2013). Adiponectin mediates the metabolic effects of FGF21 on glucose homeostasis and insulin sensitivity in mice. Cell Metab 17(5): 779-789. DOI: 10.1016/j.cmet.2013.04.005.

Lin Z, Wu Z, Yin X, Liu Y, Yan X, Lin S, et al. (2010). Serum levels of FGF-21 are increased in coronary heart disease patients and are independently associated with adverse lipid profile. PLoS One 5(12): e15534. DOI: 10.1371/journal.pone.0015534.

Liu S, Quarles LD (2007). How fibroblast growth factor 23 works. J Am Soc Nephrol 18(6): 1637-1647. DOI: 10.1681/ ASN.2007010068.

Marchelek-Myśliwiec M, Dziedziejko V, Nowosiad-Magda M, Dołęgowska K, Dołęgowska B, Pawlik A, et al. (2019a). Chronic kidney disease is associated with increased plasma levels of fibroblast growth factors 19 and 21. Kidney Blood Press Res 44: 1207-1218. DOI: 10.1159/000502647.

Marchelek-Myśliwiec M, Dziedziejko V, Nowosiad-Magda M, Wiśniewska M, Safranow K, Pawlik A, et al. (2019b). Bone metabolism parameters in haemodialysis patients with chronic kidney disease and in patients after kidney transplantation. Physiol Res 68(6): 947-954. DOI: 10.33549/physiolres.934118.

Mraz M, Bartlova M, Lacinova Z, Michalsky D, Kasalicky M, Haluzikova D, et al. (2009). Serum concentrations and tissue expression of a novel endocrine regulator fibroblast growth factor-21 in patients with type 2 diabetes and obesity. Clin Endocrinol (Oxf) 71(3): 369-375. DOI: 10.1111/j.13652265.2008.03502.x.

Nishimura T, Nakatake Y, Konishi M, Itoh N (2000). Identification of a novel FGF, FGF-21, preferentially expressed in the liver. Biochim Biophys Acta 1492(1): 203-206. DOI: 10.1016/s01674781(00)00067-1.

Reiche M, Bachmann A, Lössner U, Blüher M, Stumvoll M, Fasshauer M (2010). Fibroblast growth factor 19 serum levels: relation to renal function and metabolic parameters. Horm Metab Res 42(3): 178-181. DOI: 10.1055/s-0029-1243249.

Sit D, Tanriverdi E, Kayabasi H, Erdem M, Sari H (2018). Is FGF23 effective on insulin resistance in individuals with metabolic syndrome? Horm Mol Biol Clin Investig 35(2) pii: /j/ hmbci.2018.35.issue-2/hmbci-2018-0018/hmbci-2018-0018.xml. DOI: 10.1515/hmbci-2018-0018.

Spoto B, Pisano A, Zocalli C (2016). Insulin resistance in chronic kidney disease: a systematic review. Am J Physiol Renal Physiol 311(6): F1087-F1108. DOI: 10.1152/ajprenal.00340.2016.

Stein S, Bachmann A, Lössner U, Kratzsch J, Blüher M, Stumvoll M, et al. (2009). Serum levels of the adipokine FGF21 depend on renal function. Diabetes Care 32(1): 126-128. DOI: 10.2337/dc081054.

Strowski MZ (2017). Impact of FGF21 on glycemic control. Horm Mol Biol Clin Investig 30(2) pii: /j/hmbci.2017.30.issue-2/ hmbci-2017-0001/hmbci-2017-0001.xml. DOI: 10.1515/ hmbci-2017-0001. 
Suassuna PGA, de Paula RB, Sanders-Pinheiro H, Moe OW, Hu MC (2019). Fibroblast growth factor 21 in chronic kidney disease. J Nephrol 32(3): 365-377. DOI: 10.1007/s40620-018-0550-y.

Tanajak P, Pongkan W, Chattipakorn SC, Chattipakorn N (2018). Increased plasma FGF21 level as an early biomarker for insulin resistance and metabolic disturbance in obese insulin-resistant rats. Diab Vasc Dis Res 15(3): 263-269. DOI: $10.1177 / 1479164118757152$.

Tomlinson E, Fu L, John L, Hultgren B, Huang X, Renz M, et al. (2002). Transgenic mice expressing human fibroblast growth factor-19 display increased metabolic rate and decreased adiposity. Endocrinology 143(5): 1741-1747. DOI: 10.1210/ endo.143.5.8850.

Voytovich MH, Asberg A, Hjelmesaeth J, Jenssen T, Hartmann A (2006). Association between insulin resistance and endothelial dysfunction in renal transplant recipients. Clin Transplant 20(2) 195-199. DOI: 10.1111/j.1399-0012.2005.00465.x.

Wojcik M, Dolezal-Oltarzewska K, Janus D, Drozdz D, Sztefko K, Starzyk JB (2012). FGF23 contributes to insulin sensitivity in obese adolescents - preliminary results. Clin Endocrinol (Oxf) 77(4): 537-540. DOI: 10.1111/j.1365-2265.2011.04299.x.

Zaheer S, de Boer IH, Allison M, Brown JM, Psaty BM, RobinsonCohen C, et al. (2017). Fibroblast Growth Factor 23, Mineral Metabolism, and Adiposity in Normal Kidney Function. J Clin Endocrinol Metab 102(4): 1387-1395. DOI: 10.1210/jc.20163563.

Zhang F, Yu L, Lin X, Cheng P, He L, Li X, et al. (2015). Minireview: Roles of Fibroblast Growth Factors 19 and 21 in Metabolic Regulation and Chronic Diseases. Mol Endocrinol 29(10): 1400-1413. DOI: 10.1210/me.2015-1155. 